\title{
Da economia tradicional do bem-estar à Abordagem das Capacitações e a importância da equidade em saúde para o desenvolvimento humano
}

From traditional welfare economics to the Capabilities Approach and the relevance of equity in health to human development

Giana Silva Giacomelli

Universidade Federal de Santa Maria

Solange Regina Marin

Universidade Federal de Santa Catarina

Paulo Ricardo Feistel

Universidade Federal de Santa Maria

\section{Abstract}

Given the importance of broadening the vision of economy based on the maximization of utility and income, this article aims at incorporating the concept of equity in health and its importance in the economic discussion on human development, through a literature trajectory that begins in the traditional welfare theory and arrives at the Capabilities Approach. The association of economics, through the Capabilities Approach, and the area of public health, via discussion of the social determinants of health, allows this work to contribute to the definition of important concepts for studies on equity in health. The conclusion is that the multidimensionality present in concepts of human development and equity in health allows for a rich discussion in terms of assessment of living standards in economics.

\section{Keywords}

human development; health equity; the capability approach; economics of welfare; Amartya Sen.

JEL Codes B59; O15; I15.

\section{Resumo}

Dada a importância de ampliar a visão da Economia fundamentada na maximização das utilidades e na renda dos países, o presente artigo objetiva incorporar o conceito de equidade em saúde e sua importância na discussão econômica sobre desenvolvimento humano, percorrendo uma trajetória bibliográfica que tem início na teoria tradicional do bem-estar e chega até a Abordagem das Capacitações. A associação entre a área de Economia, por meio da Abordagem das Capacitações, ea área da saúde pública, via discussão sobre os determinantes sociais de saúde, possibilita que este trabalho contribua com a definição de conceitos importantes para os estudos sobre equidade em saúde. Conclui-se que a multidimensionalidade presente nos conceitos de desenvolvimento humano e de equidade em saúde permite uma discussão rica, em termos de avaliação da vida das populações, na Economia.

\section{Palavras-chave}

desenvolvimento humano; equidade em saúde; abordagem das capacitações; economia do bem-estar; Amartya Sen.

Códigos JEL B59; O15; I15. 


\section{Introdução}

Tradicionalmente considera-se que a Ciência Econômica tem como objetivo de estudo a adequação de recursos escassos a necessidades ilimitadas dos indivíduos em uma sociedade; busca encontrar o ponto que representa o máximo bem-estar desses indivíduos e alcançar a eficiência econômica. A avaliação do bem-estar, pela corrente econômica tradicional, está relacionada ao espaço das utilidades e ao aumento da riqueza monetária das nações. Porém, críticas a esse pensamento deram origem à Abordagem das Capacitações que ultrapassa a visão do êxito dos indivíduos a partir do espaço das utilidades.

A Abordagem das Capacitações apresenta uma concepção de desenvolvimento humano, na qual valoriza a liberdade substantiva dos indivíduos, e não apenas a liberdade de transacionar no mercado (Sen, 2010a). Ao ampliar a avaliação do êxito social, por meio de uma análise de desenvolvimento humano e não apenas econômico, a Abordagem das Capacitações insere na discussão econômica questões relativas às considerações de justiça e de eficiência predominantes na Economia.

O questionamento que norteia a argumentaçãodo presente artigo é: como o conceito de equidade em saúde pode ser incorporado na discussão sobre desenvolvimento humano na Economia? Visto que a saúde pode ser considerada um bem com fim em si mesmo, assim como um ingrediente fundamental para o "ser" e o "fazer" das pessoas (Woodward; Kawachi, 2000). Para responder a este problema, realizou-se uma revisão teórica do conceito de bem-estar econômico, desde a teoria tradicional do bem-estar até a Abordagem das Capacitações.

O tema saúde foi abordado no âmbito da Economia por autores como Arrow (1963) e Grossman (1972), no entanto, o foco das análises estava no capital humano e não propriamente na discussão sobre a relevância da equidade em saúde. A equidade em saúde tem sido estudada especialmente sob a ótica da epidemiologia e da saúde pública, no entanto, tais estudos apresentam lacunas conceituais, especialmente com relação à definição de igualdade; justiça; diferenças e desigualdades em saúde (Vieira-da-Silva; Almeida Filho, 2009).

A equidade em saúde está fundamentalmente relacionada à busca pela inexistência de desigualdades em saúde oriundas de diferenças sociais, o que inclui não apenas a desigualdade de acesso a serviços de saúde, mas também às diferenças evitáveis existentes no contexto geral de vida dos in- 
divíduos, que interferem no alcance do seu melhor nível de saúde, independentemente das variações biológicas que possam existir (Whitehead, 1990).

Fundamentado nos conceitos de justiça e equidade, presentes na Abordagem das Capacitações, este artigo tem o objetivo de incorporar o conceito de equidade em saúde, e sua importância na discussão sobre desenvolvimento humano na Economia. Segundo Whitehead, a equidade em saúde é atingida quando todos os indivíduos têm uma oportunidade justa de alcançar seu potencial pleno de saúde.

A principal contribuição do presente trabalho é discutir a importância da equidade em saúde, no âmbito da Economia, a partir de um arcabouço teórico que incorpore a reflexão sobre temas como justiça, equidade e eficiência na análise do bem-estar e permitira identificaçãoda diversidade de dimensões que compreendem a vida das pessoas e o alcance do desenvolvimento humano. A multidimensionalidade do conceito de equidade em saúde a torna um objetivo "central" para alcançar o fim último do desenvolvimento humano, que é melhorar a vida das pessoas (Sen, 2010a).

O artigo é composto por três seções, além desta introdução. A próxima seção tem como objetivo apresentar a abordagem do bem-estar na teoria econômica tradicional e as críticas correspondentes a esta corrente teórica que deram origem à Abordagem das Capacitações, apresentada na terceira seção do trabalho, que contempla também o conceito de desenvolvimento humano, justiça e equidade. A quarta seção aborda o conceito de equidade em saúde e argumenta sobre a sua importância para o desenvolvimento humano, conceituado a partir da Abordagem das Capacitações. Por fim, serão apresentadas algumas considerações finais.

\section{A teoria tradicional do bem-estar: da origem às críticas}

\subsection{Teoria tradicional do bem-estar e a eficiência de Pareto}

De acordo com Samuelson (1983), a Economia, desde sua origem, teve como preocupação questões de políticas administrativas e do bem-estar. Para o autor, depois da obra de Adam Smith (2003), A Riqueza das Nações, publicada originalmente em 1776, a concorrência perfeita passou a ser considerada a representação de uma situação ótima, "patrocinadora" do 
bem-estar social. Adam Smith foi o precursor da corrente teórica que recebeu a alcunha de Escola Clássica dentro da Economia, que teve seu auge durante os séculos XVIII e XIX e forneceu a base para todas as correntes teóricas que se formaram dentro da Economia.

No século XX, apesar da continuidade de uma escola de escritores que acreditava que a Economia poderia cumprir função "política", surge outra que divergedesse pensamento, da qual se originou a teoria tradicional do bem-estar, que dividiu-se em "economia do bem-estar" e "nova economia do bem-estar".

É importante definir que a crítica realizada neste trabalho refere-se a "nova economia do bem-estar", corrente teórica representada por Vilfredo Pareto (Samuelson, 1983), que consolidou a utilidade como única dimensão para avaliar o bem-estar, em detrimento de fatores ligados à vida real dos indivíduos (Sen, 1999a). Uma vez que, o presente trabalho argumenta sobre a importância de considerar a diversidade de aspectos da vida valorizadospelas pessoas na avaliação do bem-estar individual e social.

A preocupação com o bem-estar dos indivíduos é, tradicionalmente, denotada pela avaliação das utilidades que as pessoas conseguem alcançar, em determinada economia, tendo acesso a determinadas cestas de bens (Sen, 1999a). Apesar de ter como objetivo a maximização do bem-estar dos indivíduos, a teoria tradicional do bem-estar procura distanciar-se de questões valorativas, morais e éticas, com o objetivo de construir regras universais para a avaliação do bem-estar.

Para Sen, a teoria tradicional do bem-estar adotou inicialmente a soma total de utilidade, criada como critério de avaliação, e desconsiderou qualquer outro fator como possuidor de valor intrínseco. Porém, a partir da década de 1930 esse critério passou a ser questionado com relação à necessidade de realizar comparações interpessoais ${ }^{1}$. $\bigcirc$ teórico afirma que no momento em que a necessidade de comparações interpessoais passou a ser questionada no ambiente econômico, o critério de avaliação que sobrevive é o "Ótimo de Pareto", uma vez que, ao tratar as utilidades individuais de forma ordinal, evitaria as comparações entre os indivíduos. Conforme esse critério, o êxito de uma situação é atingido se, e somente se, for impossível aumentar a utilidade de uma pessoa sem reduzir a utilidade de outra.

1 Lionel Robbins $(1935 ; 1938)$ exerce considerável influência na consolidação deste questionamento, ao argumentar sobre a impossibilidade de realizar comparações interpessoais de utilidade, sob o ponto de vista da economia positiva, alega que tais comparações constituem-se em juízo de valor e exigem considerar que todos os indivíduos têm capacidade para atingir níveis iguais de satisfação. 
O critério de eficiência de Pareto baseia-se no espaço das utilidades, ou "ofelimidade", que significa, de acordo com Pareto (1987), a utilidade ligada ao sentimento de prazer gerado ao indivíduo pela satisfação de uma necessidade, pode ser sinônimo do termo "utilidade econômica" e difere do sentido corrente da palavra utilidade. Pareto define que o problema econômico está relacionado à oposição entre "gostos" e "obstáculos"; cada indivíduo se esforça para satisfazer seus gostos tanto quanto seja possível em vista dos obstáculos que se apresentam, e tal satisfação representará o alcance de um estado de bem-estar para si, e é atingida no ponto em que não lhe seja conveniente nem ir além e nem ficar aquém da situação que alcançou via algum mecanismo de troca.

Agafanow (2007) expõe que a eficiência no sentido de Pareto consiste na ideia de que seria possível organizar a economia, de acordo com as regras sociais vigentes, de tal forma que fosse possível atingir o máximo grau de bem-estar dos indivíduos. Este nível Ótimo de bem-estar seria representado por uma situação na qual não existiria melhoria alguma a ser feita que provocasse o aumento do nível de utilidade de um indivíduo sem piorar o nível de outro.

Mukhopadhaya (2001) afirma que comumente a interpretação de eficiência está baseada no critério de Ótimo de Pareto, porém, avalia que tal critério evita as comparações interpessoais, por exemplo, nenhuma tentativa é feita de comparação entre o grau de riqueza para indivíduos que se encontram em situações mais favoráveis e para aqueles em situações desfavoráveis. Mukhopadhaya (2001) acredita que todo esse equilíbrio de ganhos e perdas individuais é descartado, quando a análise da eficiência é feita a partir do princípio de Pareto.

Para Samuelson (1983), Pareto dispensa a soma das utilidades dos diferentes indivíduos, justamente pelo fato de que tal ato exigiria a realização de comparações interpessoais e atribuição de pesos aos níveis de utilidades de cada indivíduo. Com relação a essa característica do ótimo paretiano, de não permitir comparações interpessoais, Sen (1999a) exemplifica que pode existir um arranjo social no qual existam pessoas que vivem na absoluta pobreza enquanto outras em abundante riqueza. Se avaliado pelo critério de Pareto, será considerado eficiente desde que as pessoas na pior situação não possam melhorar suas condições sem reduzir o luxo dos mais favorecidos. Para ele, tal fato representa a limitação da avaliação do êxito a partir desse critério. 
Outra objeção ao critério de Pareto, que Samuelson (1983) argumenta ser a mais importante, e que recai sobre a economia do bem-estar, está no fato de que não fica claro que não existe um único ponto ótimo, mas sim uma infinidade de pontos ótimos que constituem a "curva de contrato". Desta forma, não permite que se avalie qual dos pontos da curva de contrato é o melhor, ou seja, efetivamente mais ou menos eficiente.

O próximo item aprofunda as críticas à teoria tradicional do bem-estar e ao critério que adotou para avaliar a eficiência em termos de bem-estar. Tais críticas possibilitaram a introdução de teorias alternativas à teoria tradicional do bem-estar no universo da Ciência Econômica.

\subsection{Críticas à teoria tradicional do bem-estar e ao critério de Pareto}

Para além das críticas relacionadas à formalização da teoria tradicional do bem-estar e seu critério de eficiência, existem as críticas que abordam o teor ético e moral dessa teoria. Como Hausman e Mcpherson (2006), que argumentam sobre as peculiaridades de algumas considerações que são típicas da Teoria tradicional do bem-estar, a saber: foco em resultados econômicos, em detrimento do processo para chegar a tais resultados; avaliação econômica realizada a partir de uma única dimensão; foco no indivíduo, sem considerar o ambiente no qual está inserido; suposição de um mercado livre regulador e foco puramente no benefício econômico das ações. Para os autores, tais características denotam uma avaliação superficial do bem-estar dos indivíduos.

Sen (1999a) critica o afastamento das questões éticas que a economia tradicional do bem-estar procurou manter; a adoção do auto interesse como único motivador das ações humanas e a impossibilidade de comparações interpessoais. Tais comparações foram consideradas pela teoria tradicional do bem-estar como questões normativas ou éticas, que não diziam respeito ao estudo da Economia, então tratadas como questões sem sentido. Para Sen (1999a), a Ética apresenta uma rica gama de contribuições para a economia do bem-estar, especialmente no sentido de entender o comportamento humano.

Ao considerar os agentes como seres egoístas em busca da satisfação própria, para Hausman e Mcpherson (2006), a teoria tradicional do bem-estar desconsidera que as pessoas atuam por fatores além do puro bem- 
-estar próprio, e podem apresentar características altruístas ou até mesmo maléficas. Outra objeção que apresentam é quanto ao fato de que, ao contrário da suposição da teoria do bem-estar, as pessoas não possuem o conhecimento completo de todas as informações necessárias para tomar uma decisão e, por vezes, podem preferir "coisas" prejudiciais a si mesmas por falta de conhecimento ou por que acreditam que lhes será benéfico. Além disso, Hausman e Mcpherson afirmam que as preferências das pessoas sofrem influências e mudam ao longo do tempo e conforme as circunstâncias em que vivem, fato desconsiderado pela economia do bem-estar.

Segundo Sen, a corrente "Welfarista" concebe o bem-estar como algo intrinsecamente importante, representado pela utilidade, e esta é considerada a única fonte de valor para os indivíduos. Sen (1999a, p.63) acredita que existem duas críticas importantes a serem feitas a este pensamento, a saber: "o bem-estar não é a única coisa valiosa" e "a utilidade não representa adequadamente o bem-estar".

Esse autor argumenta que a teoria do bem-estar falha ao considerar a utilidade como única fonte de valor e adotá-la como representante do bem-estar dos indivíduos, e este último como reflexo do êxito social, o que resulta do crédito dado por esta teoria ao fato de que os indivíduos atuam puramente motivados pelo auto interesse. Ainda de acordo com Sen (1999a), ao agir, as pessoas levam em consideração dois aspectos - o de agente e o de bem-estar. $O$ primeiro diz respeito a fatores como valores, cultura, sentimento de comprometimento e objetivos que cada indivíduo tem. O segundo está relacionado ao agir em busca do bem-estar individual, uma vez que as pessoas buscam também o seu bem-estar. Porém, estes dois papéis são intrínsecos aos indivíduos e atuam juntos na motivação do comportamento humano e não de forma desconexa.

Desta forma, ao adotar o auto interesse e a busca pelo máximo bem-estar, como os motores das ações dos indivíduos, a teoria econômica do bem-estar desconsidera a condição de agente das pessoas. A partir da condição de agente é que a pessoa orienta-se, e é motivada por outros fatores, que não apenas o seu próprio bem-estar, mas também por questões que considera como importantes para si, em termos de contexto de vida.

Além disso, Sen acredita que avaliar o bem-estar simplesmente a partir da satisfação dos desejos dos indivíduos pode distorcer o sentido da "satisfação", uma vez que, ao não permitir comparações interpessoais, tal avaliação não consegue captar como um arranjo social é visto por diferentes 
pessoas, que carregam consigo uma história própria baseada no seu contexto de vida, nas suas experiências, nos valores e cultura que circundam o meio no qual vivem.

Segundo Agafanow (2007, p. 94), "La eficiencia es un concepto central en La ciencia económica actual, pero no está fundado tan sólidamente como creen los economistas profesionales: de hecho, no hay consenso sobre qué es una economía eficiente." Para o autor, Amartya Sen seguiu um bom caminho ao abandonar os espaços das utilidades e desenvolver sua teoria no espaço das capacitações.

O critério de eficiência de um arranjo social, de acordo com Makdissi (2006), deve estar adequado ao espaço adotado pelos objetivos sociais, na avaliação de justiça social, e destes dependerá também a avaliação da eficiência. Segundo Makdissi , o Ótimo de Pareto é apenas uma das formas de avaliar um arranjo social, e a importância de fato está em definir primeiramente a partir de qual espaço de avaliação social será realizada a análise.

A avaliação do bem-estar dos indivíduos, de acordo com Hausman e Mcpherson (2006), pode seguir diferentes linhas de consideração, é possível que se adote uma ótica substantiva ou uma ótica formal para a avaliação do bem-estar. A visão formal, aquela baseada na satisfação de preferências e maximização de utilidades, é predominante na teoria tradicional do bem-estar. Já a Abordagem das Capacitações marca uma ruptura com o espaço informacional adotado pela teoria tradicional do bem-estar. A próxima seção discorre sobre a Abordagem das Capacitações, o conceito de desenvolvimento humano e a ideia de justiça e equidade de Amartya Sen.

\section{Abordagem das Capacitações e a ideia de justiça de Amartya Sen}

\subsection{A Abordagem das Capacitações}

A Abordagem das Capacitações foi desenvolvida paralelamente por duas Ciências; na Filosofia política, por Martha Nussbaum e, na Economia, pelo economista indiano Amartya Sen (1983, 1988, 2000, 2008), contexto no qual a abordagem representa uma ruptura com os conceitos e espaços utilizados pela corrente teórica tradicional do bem-estar. De acordo com Gasper (1997), a Abordagem das Capacitações surge, na Economia, como 
resultado das críticas tecidas à teoria tradicional do bem-estar em torno da década de 1970. Gasper afirma que Amartya Sen ampliou e alterou a visão tradicional da microeconomia sobre a relação entre indivíduo, renda e bem-estar.

Para Sen (2007), sua abordagem diferencia-se de outras pelo foco informacional utilizado para avaliar o bem-estar. Cita como exemplo de espaços focais utilizados por outras abordagens a utilidade individual; a riqueza absoluta ou relativa; as liberdades negativas; os meios para atingir a liberdade e a igualdade de recursos. Sen (2008) afirma que as abordagens em geral, que tratam de analisar o bem-estar dos indivíduos, adotam variáveis instrumentais, focam em fatores que são meios para o alcance do bem-estar, como a renda individual; a riqueza de um país; os bens-primários e acesso a recursos, enquanto que a Abordagem das Capacitações realiza sua avaliação com base em elementos que constituem o bem-estar: os funcionamentos.

A Abordagem das Capacitações parte de uma concepção de que a vida é uma combinação de diversas formas de "ser" e "fazer", e a qualidade da vida das pessoas é avaliada a partir das suas capacitações para alcançar funcionamentos que são valiosos para si (Sen, 2007). O bem-estar é concebido, por Sen (2008), em termos da qualidade do "estado" de uma pessoa. O termo "estado" é aqui empregado no sentido constitutivo de um indivíduo, ou seja, "o que ele é"; "como é" e "como está".

Dois pilares fundamentais embasam a constituição da Abordagem das Capacitações, são eles: funcionamentos (functionings) e capacitação (capability). Conforme Sen (2008), os funcionamentos são os elementos constitutivos do "estado" de ser das pessoas, representam a noção mais primitiva da Abordagem das Capacitações (Sen, 2007); e as capacitações representam quais são os conjuntos de funcionamentos que a pessoa escolheu exercer.

Sen $(1985,1988)$ acredita que os funcionamentos são os elementos constitutivos do bem-estar, servem como exemplo deles, comer, falar, pensar, escutar, entre outros. A disponibilidade de funcionamentos pode diferir para cada indivíduo, e influencia nas opções que cada um terá para atingir o seu bem-estar. Para Sen (1988), as diferentes opções de escolha ou disponibilidades de funcionamentos definirão quais indivíduos terão maior liberdade e quais sofrerão privações, tal fato diversifica o nível de bem-estar que poderá ser atingido por cada um. 
As capacitações, por sua vez, conforme Sen (2007), refletem as combinações possíveis de funcionamentos que uma pessoa consegue realizar. Dessa forma, Sen (1990) apresenta a capacitação como o reflexo da liberdade individual da escolha por uma forma de vida. A partir do ponto em que concebe as capacitações como resultantes das diversas combinações de funcionamentos que um indivíduo escolhe exercer, e como representantes da sua concepção de vida; dos valores nos quais acredita e da sua liberdade substantiva. Para Sen (1988), a liberdade de escolha está relacionada ao modo de vida que cada indivíduo considera importante ou "correto" levar, reflete seus valores e proporciona a expansão das suas capacitações. A expansão das capacitações, por sua vez, é o que Sen (1988) considera como desenvolvimento humano; e reflete a expansão das liberdades das pessoas.

Costa (2006) argumenta que além dos funcionamentos e capacitações, os intitulamentos (entitlements) também constituem o bem-estar, sob a ótica de Amartya Sen, porém os intitulamentos não representam um fim em si, mas um meio para atingi-lo. De acordo com Robeyns (2005), a Abordagem das Capacitações apresenta, como uma característica marcante, a distinção entre os meios e os funcionamentos e capacitações. A importância dos meios está nas possibilidades que geram de melhorar a vida das pessoas, quando proporcionam que estas realizem os funcionamentos que consideram importantes para si (Robeyns, 2005; Sen, 1999b).

Para Sen (1999b), os intitulamentos refletem as relações de propriedades vigentes em uma sociedade, e por isso a avaliação da carência ou não de bens e serviços exige primeiramente compreender a estrutura de propriedade vigente na sociedade analisada, e não apenas ter conhecimento da quantidade de bens que nela são produzidos. "A capacidade de uma pessoa de dispor de alimentos - na verdade, de dispor de qualquer mercadoria que deseje adquirir ou ter - depende das relações de concessão de direitos que governam a posse e o uso nessa sociedade." (Sen, 1999b, p.216).

De acordo com Kuhn (2004), a ideia de intitulamentos deriva dos dois conceitos fundamentais da Abordagem das Capacitações, os funcionamentos e as capacitações, através dos quais Amartya Sen concebe o processo de desenvolvimento humano. Em sua argumentação sobre a Abordagem das Capacitações, Sen $(1990,2012)$ direciona seu foco sobre os conceitos de funcionamentos e capacitações para avaliar o bem-estar individual, acreditando que são esses elementos que constituem a vida e a liberdade das pessoas. 
Para Sen (2012), o espaço de avaliação da Abordagem das Capacitações pode ser considerado o espaço dos funcionamentos realizados ou o do conjunto capacitário, o espaço dos funcionamentos realizados representa o que uma pessoa realmente conseguiu fazer. Já, conforme Sen (2008), o conjunto capacitário reflete, no espaço dos funcionamentos, a liberdade de a pessoa escolher entre vidas possíveis, assim como, no espaço de mercadorias, o conjunto orçamentário representa a liberdade de um indivíduo para comprar pacotes de mercadorias. Nesse sentido, assim como a renda da qual uma pessoa dispõe limitará suas escolhas, no campo das mercadorias, as diversas combinações de funcionamentos, disponíveis a uma pessoa, limitarão sua escolha de modos de vida e, em consequência influenciarão seu bem-estar. $\bigcirc$ conjunto capacitário reflete a liberdade substantiva do indivíduo, uma vez que permite visualizar as suas escolhas frente às diversas opções que tem a sua disposição (Sen, 2008).

A amplitude propiciada pela Abordagem das Capacitações sobrecomo entender a vida dos indivíduos possibilita um novo olhar para o desenvolvimento na Economia, e concebe o desenvolvimento humano. Segundo Sen (1988), a Abordagem das Capacitações é fundamental ao conceito de desenvolvimento humano, por representar uma ampliação da avaliação do desenvolvimento baseada no puro bem-estar, prazer e satisfação das pessoas.

Sen (2011) alerta para o fato de que avaliar o bem-estar de um indivíduo a partir da ótica das capacitações exige a compreensão de dois fatores importantes, a saber; a diferença entre realização e liberdade dos aspectos de agência e bem-estar. Sen (1985) define que o ser humano é constituído por um papel de agente e outro de bem-estar; ambos os aspectos devem ser considerados quando se trata de avaliar o indivíduo. O bem-estar, apesar de ser uma variável importante, não é exclusiva, e existem outras variáveis que também devem ser lavadas em consideração (Sen, 1985; 1999a).

Nesse contexto, Sen (1985) introduz a importância de avaliar também o aspecto de agência do indivíduo. Tal aspecto refere-se à autonomia e liberdade individual, e exerce influências, que podem ser positivas ou negativas, sobre o aspecto do bem-estar. $O$ aspecto de agência, segundo Sen, diz respeito à forma de vida que uma pessoa considera valorosa levar, entram em questão os seus valores éticos e morais. Ao realizar o seu aspecto de agente, o indivíduo poderá praticar ações que não necessariamente aumentam o seu bem-estar, pelo contrário, podem até atuar de forma que seu bem-estar seja reduzido. 
O aspecto de bem-estar de uma pessoa permite a construção de um conceito particular de liberdade, a liberdade de bem-estar, que excede a avaliação do indivíduo apenas pela realização de bem-estar. Sen (2012) diferencia a liberdade de bem-estar e a liberdade da condição de agente; a primeira refere-se à liberdade que uma pessoa tem para realizar aquelas coisas que são constitutivas de seu bem-estar. Conforme a Abordagem das Capacitações, a liberdade de bem-estar está relacionada ao conjunto capacitário de uma pessoa, ou seja, às possibilidades que um indivíduo tem de escolher, entre as diversas combinações possíveis de funcionamentos que estejam disponíveis para si, o que possa gerar bem-estar e que seja valorosos para a sua vida.

A liberdade da condição de agente refere-se à liberdade para atingir as realizações que se valoriza e se busca produzir, trata-se de atingir realizações mais amplas que o próprio bem-estar (Sen, 2012). De acordo com Sen (1985), a liberdade de agente não está vinculada ao alcance de um objetivo específico, mas sim a realizações que podem, por exemplo, estar relacionadas com questões sociais que representam os valores morais e éticos e o senso de responsabilidade defendido pelo indivíduo.

Apesar de considerar que o aspecto de agência é mais abrangente e, muitas vezes engloba o bem-estar, o autor argumenta que ambos são importantes na avaliação de um indivíduo, e devem ser tratados como conceitos diferentes. Sen (1985) resume que o aspecto de bem-estar é importante em termos de analisar os benefícios que uma pessoa atinge; o aspecto de agência é importante no sentido de permitir a avaliação de o que uma pessoa consegue fazer conforme sua concepção de bem, independente de obter benefícios particulares com isso.

Para Sen (1999b), a avaliação da vida das pessoas a partir dos aspectos: "realização de bem-estar", "liberdade de bem-estar", "realização da condição de agente" e "liberdade da condição de agente", permite ultrapassar a visão instrumental da liberdade, e constitui uma avaliação a partir das liberdades substantivas dos indivíduos.

De acordo com Sen (2010a), a Abordagem das Capacitações é a abordagem normativa que guia sua construção do conceito de "desenvolvimento como liberdade", e essa abordagem considera as liberdades substantivas essenciais para o êxito de uma pessoa. O próximo item desta seção tem como foco apresentar o conceito de desenvolvimento humano, derivado da Abordagem das Capacitações, que permite fundamentar a importância da equidade em saúde na discussão econômica. 


\subsection{0 desenvolvimento humano sob a ótica da Abordagem das Capacitações}

De acordo com Sen (2000), há séculos existe um "duelo" entre abordagens do desenvolvimento totalmente contrárias ou totalmente a favor da liberdade de mercado. A Abordagem das Capacitações é a favor da liberdade, pois concebe o desenvolvimento humano como a expansão das liberdades substantivas. Porém, a consideração da liberdade, via Abordagem das Capacitações, ultrapassa a avaliação da liberdade de mercado que, apesar de ser importante para o crescimento econômico, limita a avaliação da liberdade que realmente as pessoas desfrutam e não representa o desenvolvimento humano. A Abordagem das Capacitações oferece argumentação sobre a importância de focar também em outras liberdades, além da liberdade econômica, e abrange liberdades, como, as sociais e políticas, que melhoram e enriquecem a vida das pessoas.

Para Sen (1983), os fatores econômicos são, no processo de desenvolvimento humano, meios para atingi-lo, já que, de alguma forma, podem possibilitar a expansão das capacitações dos indivíduos, mas não representam o objetivo final desse desenvolvimento que é a melhoria da vida das pessoas. Conforme Sen (2000), a Abordagem das Capacitações propõe a integração entre considerações econômicas, sociais e políticas na investigação do processo de desenvolvimento humano. $O$ desenvolvimento humano, sob a ótica da expansão das liberdades, proporciona uma apreciação ampla das relações sociais, econômicas e de poder.

A Abordagem das Capacitações, para Sen (2000), entende que o desenvolvimento humano deve ser visto como o processo de expansão das liberdades reais que as pessoas desfrutam. Sen (2010a) considera que a liberdade de escolha de uma forma de vida que cada indivíduo acredita como o "melhor modo de viver", com base em seus valores, características sociais, culturais e individuais, é a finalidade última do processo de desenvolvimento humano. Tal liberdade é constituída a partir do conjunto capacitário, disponível para os indivíduos em uma sociedade, a partir do sistema econômico e social vigente, que possibilita a escolha por diferentes modos de vida.

Sendo assim, Sen (2010a) alega que é necessário buscar um equilíbrio entre Estado, mercado, instituições políticas e sociais, e defende o "caminho do meio" entre o livre mercado e a intervenção estatal. Para Sen 
(1988), a realização dos funcionamentos individuais depende não apenas de "mercadorias" de posse dos indivíduos, mas também da disponibilidade de bens públicos, aqueles comuns a todas as pessoas, e também de bens privados disponibilizados pelo Estado, como, o acesso a serviços de saúde e educação.

O crescimento econômico deve ser avaliado do ponto de vista de suas contribuições para as liberdades individuais; das possibilidades que pode oportunizar no âmbito das oportunidades sociais. De acordo com Sen (2000), superar os problemas de privações que são encontrados ainda hoje nos diversos países do mundo, independentemente de sua classificação em níveis de riqueza, é parte central do processo de desenvolvimento humano. As oportunidades econômicas, liberdades políticas, poderes sociais e condições habilitadoras em geral, como boa saúde; educação; incentivos e aperfeiçoamento de iniciativas, exercem influências sobre as escolhas dos indivíduos, terão reflexos no conjunto de funcionamentos que as pessoas exercerão durante a vida e, consequentemente, nas capacitações que desenvolverão.

A existência de privações limita o desenvolvimento humano, uma vez que limita a liberdade dos indivíduos e, por isso, a eliminação dessas privações faz parte dos fins do processo de desenvolvimento idealizado por Amartya Sen. Para Sen (2010a), a discussão política voltada para a melhoria de vida das pessoas prevê a distinção entre desigualdade de renda e desigualdade econômica. A primeira relacionada com as diferenças de recursos financeiros entre as pessoas, porém a desigualdade econômica abrange além das distinções de renda, também as desigualdades, sociais, políticas, de características individuais, enfim, as desigualdades que influenciam na conversão da posse de renda (meio) em expansão de capacitações (fim).

A Abordagem das Capacitações altera o foco unidimensional na renda nacional e per capita e procura identificar quais os espaços são mais relevantes para os indivíduos, e em que espaços devem-se buscar a igualdade, na avaliação dos arranjos sociais, com a finalidade última de melhorar as vidas humanas. A abordagem proposta por Amartya Sen introduz, na discussão econômica, uma nova forma de tratar questões de justiça e equidade que possibilita inserir a saúde como um espaço central a ser considerado na promoção do desenvolvimento humano, essa mudança de tratamento é exemplificada na seção seguinte. 


\subsection{A ideia de justiça de Amartya Sen e a equidade}

De acordo com Marin e Quintana (2010), a concepção normativa do desenvolvimento como expansão das capacitações humanas, desenvolvida por Sen (2010a), é fundamentada na sua crítica referente à visão utilitarista da economia tradicional do bem-estar e influenciada pela teoria da justiça de John Rawls.

A ideia de justiça argumentada por Amartya Sen difere da linha contratualista seguida por Rawls, na medida em que Sen (2011) acredita que atingir um arranjo social justo está muito mais relacionado a reduzir injustiças do que a definir "contratualmente" uma sociedade perfeitamente justa. Ele assume como foco as realizações das pessoas frente a uma "diversidade de bens" e não apenas a uma "cesta específica de bens".

Então, segundo esse autor, a teoria de justiça desenvolvida por John Rawls concebe a justiça como fundamental e anterior aos princípios de justiça, e defende que o alcance dessa justiça deve estar relacionado à noção de equidade. Ao tratar da equidade, Sen refere-se à exigência de imparcialidade que, na teoria de Rawls, é garantida pela hipotética "posição original", na qual são determinados os acordos fundamentais para a constituição de uma sociedade justa. Tais acordos seriam definidos por meio de deliberações, de um grupo de representantes desta sociedade, realizadas sob um "véu de ignorância". Este "véu" representa o desconhecimento por parte daqueles representantes sobre suas posições sociais e benefícios próprios que poderiam obter com suas decisões.

Segundo Sen (2011), Rawls defende que os princípios de justiça que emergem da deliberação realizada na posição original são os seguintes:

1) Cada pessoa tem direito igual a um esquema plenamente adequado de liberdades básicas iguais que seja compatível com um esquema similar de liberdades para todos.

2) As desigualdades sociais e econômicas devem satisfazer duas condições. Primeira, elas devem estar associadas a cargos e posições abertos a todos em condições de igualdade equitativa de oportunidades. Segunda, elas devem ser para o maior benefício dos membros menos favorecidos da sociedade (Sen, 2011, p.89).

A importância dada à liberdade individual e aos recursos para obter a liberdade substantiva na teoria rawlsiana é, conforme Marin e Quintana (2010), o principal fator que chamou a atenção de Sen para esta abordagem 
da justiça, uma vez que difere da base informacional utilitarista, ao desviar do foco nos resultados para focar nas oportunidades que as pessoas têm. Porém, Sen (2011) alerta para o fato de que a liberdade deve ser vista a partir de seu valor intrínseco e não apenas como um recurso complementar a outros recursos e, além da posse de bens primários, deve-se considerar como as pessoas conseguem transformá-los em bem-estar e liberdades.

Conforme Sen (2010a), são as falhas nas bases informacionais adotadas pelas teorias utilitarista e rawlsiana que o motivam a propor uma abordagem alternativa. Sen (1979) sugere que as lacunas deixadas pelas teorias utilitaristas e dos bens primários de Rawls sejam complementadas com a ideia, que para ele é moralmente mais relevante, de igualdade de capacitações básicas. Essa igualdade possibilita que as pessoas escolham a sua forma de vida, que não necessariamente será a mesma para todas as pessoas. Diferentes pessoas, com suas peculiaridades, têm a oportunidade de chegar a um estado que cada uma considera como o bem-estar para si.

Para Sen (2011), essa liberdade de escolha ultrapassa o sentido puro da oportunidade, traz também a responsabilidade pelas escolhas realizadas; a liberdade de escolha atinge mais do que a busca pelo próprio bem-estar e permite que cada indivíduo decida quais "coisas" têm razão para buscar e, ao mesmo tempo, assuma as consequências de suas escolhas. No contexto da equidade em saúde, Whitehead (1990) define a comportamento prejudicial oriundo de escolha restrita como um dos determinantes de diferenças injustas e evitáveis em saúde, portanto, gerador de iniquidade em saúde.

De acordo com Sen (2008, p.43), ao se tratar de igualdade é necessário fazer as perguntas "Igualdade de quê?" e "Por que a igualdade?". Tais perguntas despertam o pensamento para o conceito de equidade, pois direcionam para a elucidação de que a pura e simples igualdade pode não proporcionar o desenvolvimento humano, pois, por vezes, é geradora de desigualdades. Avaliar que tipo de "igualdade" se busca e por que motivo ela é perseguida faz despertar para o fato de que nem sempre a disposição dos mesmos recursos para indivíduos diferentes levará a um arranjo social menos injusto.

Braveman e Gruskin (2003b) argumentam que a igualdade serve como uma referência para avaliar a equidade, mas avaliar a equidade exige agrupar indivíduos em melhor e em pior situação e comparar um grupo em relação ao outro, sem o objetivo de torná-los iguais, mas de garantir, adotando o conceito de Sen (2010a), que tenham as mesmas capacitações básicas. 
Para Sen, a equidade e a justiça social figuram como complementos indispensáveis para a avaliação do êxito de uma sociedade, a partir da prosperidade econômica. Tal complementação deve se dar a partir da ação pública voltada para questões como educação, segurança e saúde, enriquecem a vida das pessoas, influencia diretamente no objetivo final do desenvolvimento humano, uma vez que contribuem com a expansão das capacitações e da qualidade de vida das pessoas (Sen, 2010a).

Conforme Ruger (2004), alguns aspectos da saúde sustentam todos os outros aspectos do desenvolvimento humano, e considera que sem uma vida saudável os outros funcionamentos não são possíveis de serem exercidos. Para o autor, as questões de saúde exercem influência inclusive no aspecto de agência dos indivíduos, na habilidade que as pessoas têm de conduzirem uma vida conforme valorizam.

Tais ações exercem influência sobre a redução de privações existentes na sociedade e ampliam o conjunto capacitário dos indivíduos, assim como possibilitam que o maior número de pessoas consiga realizar os funcionamentos que valoriza. Neste contexto é que a equidade em saúde torna-se um conceito importante na discussão econômica.Tal conceito será explanado na próxima seção e permitirá a compreensão da sua importância para o desenvolvimento humano.

\section{Equidade em saúde e desenvolvimento humano}

A saúde, no âmbito da economia, foi abordada por autores como Kenneth Arrow (1963), que apresenta como foco de seus estudos a chamada "indústria de cuidados médicos". Para Arrow, uma diversidade de fatores influencia na saúde, sendo que o cuidado médico faz parte desse conjunto, do qual também participam fatores como renda, nutrição e condições sanitárias, os quais, inclusive, são considerados mais significantes. Em seu estudo, Arrow destaca as particularidades do setor saúde e analisa a forma de operação dessa "indústria" e com que eficácia ela atende às reais necessidades da sociedade.

Outra inserção da saúde na Economia é realizada por Michael Grossman, economista americano que desenvolveu em 1972 um modelo de demanda por saúde. Grossman apresenta a visão da saúde como um estoque de capital capaz de produzir um tempo de vida saudável, e elabora seu 
modelo a partir de uma função intertemporal de um consumidor típico. De acordo com Grossman (1972), os indivíduos procuram saúde, basicamente, por dois motivos: como um bem de consumo, considerando que os dias de doença são uma fonte de "desutilidade", e como um bem de investimento, considerando que o estado de saúde determina a disponibilidade para atividades econômicas e outras.

Apesar de Arrow (1963) e Grossman (1972) incorporarem a saúde nas discussões da teoria econômica, não apresentavam como foco a questão da equidade.A preocupação com as desigualdades em saúde surge na Europa, a partir da identificação de que diferentes grupos sociais apresentavam diferentes níveis de redução das taxas de mortalidade, índice tradicionalmente utilizado para avaliar o estado de saúde da população (McCartney et al., 2013; Dahlgren; Whitehead, 1991; New Zealand, 1998). A partir destas constatações, na década de 1980, a equidade em saúde foi definida como a primeira de 38 metas dos países membros da Região Europeia da Organização Mundial da Saúde (Whitehead, 1990) e deu origem a um "grupo de estudos" desenvolvido para atingir esta meta e enfrentar os desafios das desigualdades em saúde.

Para Whitehead e Dahlgren (2007), a equidade em saúde implica que idealmente todas as pessoas, e não apenas um grupo particular, possam atingir seu potencial pleno de saúde, e que ninguém esteja em desvantagem para alcançar tal potencial por conta de sua posição social ou outra circunstância determinada socialmente. A equidade em saúde é direcionada a criar oportunidades e eliminar obstáculos para a realização do potencial de saúde de todas as pessoas (Whitehead, 1990).

Segundo Braveman e Gruskin (2003b), a equidade em saúde representa a ausência de disparidades sistemáticas na área da saúde entre grupos com diferentes níveis de vantagem ou desvantagem social. Para os autores, tais disparidades são consideradas injustas, uma vez que são determinadas por questões sociais como nível de renda, gênero, raça, religião e etnia.

Whitehead (1990) define sete determinantes das diferenças em saúde, entre esses, três determinam diferenças inevitáveis, que não configuram desigualdades ${ }^{2}$ em saúde, e trêsgeram diferenças evitáveis e injustas, representando iniquidades em saúde, são eles: comportamento prejudicial com escolha restrita; condições de trabalho e stress; e o acesso a serviços das de questões sociais e sistematicamente determinadas (Whitehead, 1990). 
básicos de saúde. Além desses, Whitehead afirma também que a seleção natural ou mobilidade social ${ }^{3}$ em saúde é um determinante misto das diferenças em saúde, pois, ainda que a doença seja inevitável, a decadência social é evitável e injusta.

O conceito de equidade em saúde de Sen (2010b) vai ao encontro do conceito de Whitehead e Dahlgren (2007), já que entende a equidade em saúde como um conceito multidimensional que abrange uma diversidade de aspectos que influenciam na vida das pessoas. Inclui,além da distribuição de recursos de saúde; a realização da saúde, a liberdade de atingir uma boa saúde e o processo que ocorre para se conseguir esse resultado, de tal forma que nenhum segmento da sociedade seja privado de atingi-lo.

A importância em se buscar a equidade em saúde está no fato de que os problemas de saúde podem proporcionar o agravamento e a perpetuação de situações de pobreza. Porém, o setor saúde tem pouco ou nenhum controle sobre os outros setores que exercem influência na saúde dos indivíduos, como educação, alimentação, emprego e habitação (Braveman; Gruskin, 2003a). Assim, faz-se necessário um olhar para além da situação de saúde em si, mas para os determinantes de tal situação com o objetivo de interromper o ciclo de pobreza e falta de saúde.

Woodward et al. (2000) acreditam que eliminar iniquidades em saúde proporciona benefícios que não estão relacionados especificamente com a situação de saúde da população, mas interferem profundamente nas conexões sociais, que permitem uma sociedade de convivência mais saudável, com menores índices de violência, com maior segurança, da qual todas as pessoas sentem-se parte e passam a sentir-se aptas e compromissadas a contribuir e zelar pela sua comunidade.

Dahlgren e Whitehead (1992) argumentam que os fatores de risco, que permitem a manutenção das iniquidades em saúde entre grupos sociais são: fatores associados aos recursos econômicos e ao ambiente físico e social em que as pessoas vivem e trabalham, como situação de pobreza, desemprego, moradia inadequada, condições de trabalho estressantes e/ou perigosas, escassez de suprimento alimentar, falta de suporte social e educacional e poluição ambiental. Um segundo grupo de fatores é associado ao comportamento individual, como o hábito de fumar, nutrição inadequada, falta de exercício, apesar de serem considerados uma escolha individual, tais fato-

3 Tendência de indivíduos doentes se moverem para baixo da escala social (Whitehead, 1990). 
res estão restritos a condições socioeconômicas, o que demonstra a importância de perceber que o ambiente social e o comportamento podem ser inter-relacionados. Outro grupo de fatores de risco, citado pelos autores, é aquele relacionado aos cuidados de saúde, representado, por exemplo, pela falta de acesso aos serviços básicos e prestação de serviços de baixa qualidade. Por fim, Dahlgren e Whitehead classificam como um fator de risco a tendência de pessoas doentes se tornarem pobres, alertam para o fato de que ainda que um indivíduo esteja em uma situação de doença que foi inevitável, a pobreza oriunda desta situação é evitável e inaceitável.

Os autores ainda argumentam que existem razões econômicas, sociais e morais que justificam a importância do foco na redução de iniquidades em saúde. Tais razões têm origem na evidência de que a morte, as deficiências, os fatores de riscos pessoais de saúde e os fatores ambientais de perigo à saúde não estão distribuídos uniformemente entre a população. Os autores alertam sobre a existência de um padrão sistemático em todos os países, no qual o fardo mais pesado das doenças e a maior exposição a perigos de saúde recaem sobre os grupos da população que vivem em situações de maior desvantagem. Kliksberg (2010) oferece estratégias para se atingir a equidade em saúde, entre elas elenca a importância da participação do Estado, por meio de políticas públicas, para solucionar os problemas gerados pelas iniquidades em saúde. Afirma que a participação dos gastos em saúde, na composição dos gastos públicos totais, é determinante dos diferentes níveis de desenvolvimento dos países.

Dahlgren e Whitehead (1991) elaboraram um Modelo de Determinantes Sociais de Saúde que distribui em níveis de intervenções políticas aqueles fatores que consideram como determinantes da situação de saúde de grupos de indivíduos, esse modelo está representado pela Figura 1.

O primeiro nível de determinantes pertence ao ambiente estrutural principal, a esfera macroeconômica, onde os indivíduos estão inseridos. A camada a seguir representa as condições materiais e sociais em que as pessoas vivem e trabalham, que são determinadas por várias questões como educação, habitação, alimentação, acesso a serviços de saúde, saneamento, emprego, ambiente de trabalho e desemprego.

O terceiro nível do Modelo de Determinantes Sociais de Dahlgren e Whitehead (1991) é constituído pela relação com família, amigos e a comunidade local; o quarto nível representa o estilo de vida que as pessoas adotam, como as escolhas pelo tipo de alimentação, prática de esportes e 
hábitos saudáveis ou prejudiciais à saúde. Para os autores, os quatro níveis são passíveis de controle por meio de intervenções políticas. No entanto, o nível mais interno do diagrama está relacionado a questões como idade, sexo, fatores hereditários e genéticos que são de mais difícil controle por meio de políticas, mas devem ser levados em conta quando se busca a equidade em saúde, pois sofrem influencias do contexto estrutural no qual as pessoas vivem.

Figura 1 The main determinants of health

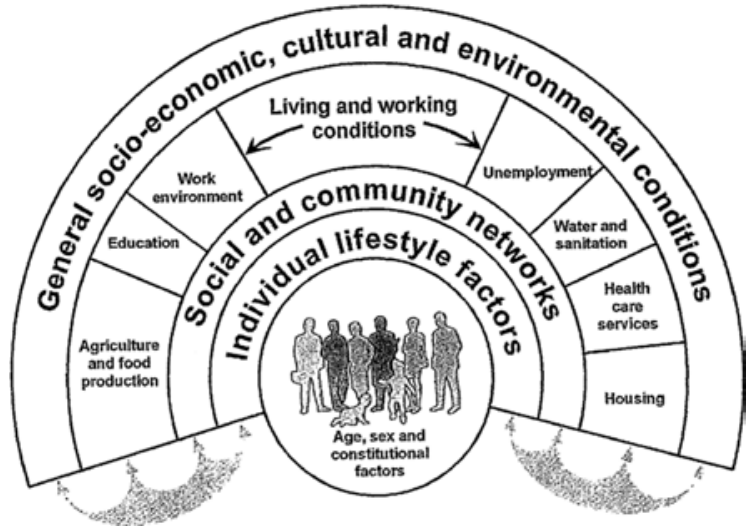

Fonte: Dahlgren e Whitehead (1991)

Para Dahlgren e Whitehead (1992) o enfrentamento do problema da iniquidade em saúde exige que as causas de tais iniquidades sejam levantadas. Os autores, fundamentados em Whitehead (1990), apresentam fatores causadores de iniquidades em saúde, que consideram evitáveis e inaceitáveis. Acreditam que o ponto chave para a definição de políticas, para reduzir as iniquidades em saúde, está em atuar sobre os fatores de risco de forma a melhorar potencialmente a saúde, especialmente das pessoas de grupos sociais em desvantagens, por que é nesses grupos que os fatores de riscos estão mais concentrados.

De acordo Dahlgren e Whitehed (1991), a identificação da existência de uma divisão da situação de saúde dentro dos países levou nações como Suécia e Holanda a definir políticas públicas que tinham como meta principal atingir equidade em saúde. Na Suécia, em 1990, foi aprovado um projeto de lei que definia a redução das iniquidades em saúde como o objetivo mais importante a ser fixado no campo de políticas públicas de saúde. 
Na Holanda, a equidade em saúde passou a ser incluída na agenda política do país pela ação de um grupo de estudos do Departamento de saúde bem-estar e cultura, no ano de 1986, e as ações realizadas envolveram cinco principais pontos estratégicos: definição politicamente neutra do problema de equidade em saúde; sensibilização dos atores sociais; atualização dos fatos dentro do processo de decisão política; envolvimento de todas as partes no processo de reduzir iniquidades em saúde e planejamento e acompanhamento das ações (Dahlgren; Whitehed,1991). Tais pontos foram trabalhados em uma conferência em que cada envolvido assumiu suas responsabilidades e, posteriormente, em 1991, foram convocados a apresentar relatórios das ações realizadas para reduzir iniquidades em saúde, assim como o governo apresentaria um relatório do progresso dos seus projetos de intervenção planejados para a área (Dahlgren; Whitehed,1991).

Outro exemplo de ação na busca pela equidade em saúde é apresentado no Relatório de Desenvolvimento Humano (2013): Bangladesh, que por meio de ações voltadas para a capacitação econômica, social e política das mulheres; para a maior participação de meninas adolescentes na educação formal; desenvolvimento de programas curriculares que abordam a saúde feminina e a construção de hábitos saudáveis; além da melhoria dos serviços de saúde e promoção à saúde, atingiu níveis importantes em termos de sobrevivência infantil, a taxa de mortalidade infantil passou de 97 óbitos para 1000 nascidos vivos, em 1990, para 38 óbitos para 1000 nascidos vivos, no ano de 2010.

Encontrar indicadores ou medidas para avaliar se as políticas públicas para atingir a equidade em saúde são eficientes não é fácil, autores como Drachler et al. (2003); Wagstaff et al. (1991), Sen (1998) e relatórios como The Social, Cultural and Economic Determinants of Health in New Zealand: Action to Improve Health (New Zealand, 1998), procuram propor indicadores para avaliar a equidade em saúde ou as desigualdades em saúde em diferentes contextos.

Nos exemplo citados, é possível identificar que acima do fator saúde em si está a importância de propiciar condições para que as pessoas tenham uma vida saudável, livre de privações e com possibilidades para expandir suas liberdades. É dessa forma, com sua multidimensionalidade, que a equidade em saúde apresenta-se como um conceito intimamente relacionado ao desenvolvimento humano, concebido pela Abordagem das Capacitações, e importante para a sua efetiva realização. 
A importância dada por Sen $(2002,2010 b)$ para a equidade em saúde está relacionada ao seu conceito de desenvolvimento humano. Quando o autor assume o desenvolvimento como a expansão das capacitações dos indivíduos, a equidade em saúde torna-se uma característica intrínseca à evolução de tal processo, já que chama a atenção para os fatores mais elementares da vida humana.

As diversas dimensões que são abordadas quando se trata de equidade em saúde permitem que ambos os conceitos "conversem", na medida em que ela ultrapassa o simples acesso a cuidados de saúde em si, e atinge a saúde como uma capacitação humana (Ruger, 2004). Ao adotar tal conceito, a importância da equidade em saúde está no fato de como as pessoas conseguem transformar a saúde em bem-estar, em realização de funcionamentos que consideram valorosos, e quais condições são proporcionadas para que os indivíduos em uma sociedade consigam tal fato.

\section{Considerações finais}

Avaliar o progresso das sociedades com base apenas em níveis de renda ou utilidade dos indivíduos é algo inapropriado quando se deseja avaliar a realidade das nações. Os níveis de renda dos países são questões importantes a se considerar, no entanto, fazem parte de um grande conjunto de dimensões que compõem a vida em sociedade, e são essas dimensões em conjunto que propiciam ou não o êxito social.

O presente trabalho teve como intenção principal possibilitar a inserção do conceito de equidade em saúde na discussão econômica sobre bem-estar e desenvolvimento humano, para isso discorreu-se sobre diferentes conceitos de bem-estar adotados no decorrer da história da Economia, e manteve-se o foco entre a ótica tradicional e a ótica da Abordagem das Capacitações, associada à discussão sobre os determinantes sociais de saúde.

A base para o processo de desenvolvimento humano, de acordo com a Abordagem das Capacitações de Amartya Sen, está na liberdade que as pessoas têm de escolher qual o melhor conjunto de funcionamentos para si e, a partir daí, expandir suas capacitações. O fator saúde, por si só, está intimamente ligado à liberdade individual, já que um indivíduo saudável, física e psiquicamente, pode fazer as suas próprias escolhas. Enquanto que uma pessoa que necessita de apoio físico ou psíquico é, muitas vezes, 
parcial ou totalmente privada da liberdade, sofre desigualdades injustas, é privada de possibilidades de ser saudável e de viver uma vida de escolhas livres, devido ao contexto no qual vive.

A inserção do conceito de equidade em saúde no contexto da discussão econômica foi permitida a partir da adoção dos conceitos de bem-estar e desenvolvimento humano, adotados pela Abordagem das Capacitações, associados à discussão sobre os determinantes sociais de saúde. A equidade em saúde extrapola o pensar a situação de saúde em si mesma, relaciona-se ao contexto social no qual o processo de desenvolvimento humano deve ocorrer e ultrapassa a busca pela simples igualdade de acesso à saúde para os indivíduos.

O conceito de equidade em saúde atinge o âmbito de alocação adequada de recursos gerais, e da constituição de arranjos sociais que proporcionem a igualdade de oportunidades de escolhas, que permitam a liberdade individual e possibilitem que as pessoas façam escolhas que alcancem o seu pleno potencial de saúde (Whitehead, 1990; Braveman; Gruskin, 2003a). A equidade em saúde tem um papel fundamental no processo de desenvolvimento humano (Ruger, 2004) e apresenta-se como um vasto campo de pesquisa, que tem muito a contribuir com a definição de ações voltadas ao bem-estar social.

Entre as colaborações do presente trabalho está a de adotar um arcabouço teórico que possibilite identificar a evolução do conceito de bem-estar econômico e sua relação com a diversidade de dimensões que envolvem a vida das pessoas. Além de permitir uma discussão a partir de conceitos da Economia e da Saúde Pública, que possibilita incorporar importantes definições,como eficiência; igualdade; equidade; diferenças e desigualdades em saúde, indispensáveis para a formulação de políticas públicas relacionadas à saúde e para a avaliação do bem-estar individual e social.

\section{Referências}

AGAFANOW, A. Los Límites de la eficiencia económica en una sociedad democrática. Revista de Economía Institucional. Cuba, v.9, n.16, p. 88-119, primer sem., 2007.

ARROW, K. Uncertainty and the welfare economics ofmedical care. Am. Econ. Rev., v. 53, n. 5, p. 941-73, 1963. Disponível em: <http://www.jstor.org/discover/10.2307/1812044?u $\mathrm{id}=2 \&$ uid $=4 \&$ sid $=21102668197017>$.

BRAVEMAN, P.; GRUSKIN, S. Poverty, equity, human rights and health. Bulletin of the World 
Health Organization. v.7, n.81, p. 539-545, 2003a.

BRAVEMAN, P.; GRUSKIN, S. Defining equity in health. J Epidemiol Community Health. n.57, p. 254-258, 2003 b.

COSTA, A. M. Pobreza e vulnerabilidade de agricultores familiares de Santo Cristo/RS: uma análise da seca a partir da Abordagem das Capacitações. 2006. Dissertação (Mestrado e Desenvolvimento Rural) - Universidade Federal do Rio Grande do Sul, Faculdade de Ciências Econômicas, Porto Alegre, 2006.

DAHLGREN, G.; WHITEHEAD, M. Policies and strategies to promote equity in health: Background document to WHO - Strategy paper for Europe. Stockholm: Institute for Futures Studies, 1991.

DAHLGREN, G.; WHITEHEAD, M. Policies and strategies to promote equity in health. Copenhagen: World Health Organization. Regional Office for Europe, 1992.

DRACHLER, M. L. et al. Proposta de metodologia para selecionar indicadores de desigualdade em saúde visando definir prioridades de políticas públicas no Brasil. Ciência e Saúde Coletiva, v.8, n.2, p.461-470, 2003.

GASPER, D. Sen's capability approach and Nussbaum's capabilities ethic. Journal of International Development, v.9, n. 2, p.281-302, 1997.

GROSSMAN, Michael. On the concept of health capital and the demand for health. Journal of Political Economy, v. 80, n. 2, p.223-255, 1972. Disponível em: <http://www.jstor.org/disco ver $/ 10.2307 / 1830580$ ?uid $=2 \&$ uid $=4 \&$ sid $=21102668197017>$.

HAUSMAN, D.; MCPHERSON, M. Economic Analisys, Moral Philosophy and Public Policy. 2. ed. New York: Cambridge University Press, 2006.

KLIKSBERG, B. O que significa viver na América Latina, a mais desigual das regiões? O caso da saúde pública. In: SEN, A.K.; KLIKSBERG, B. As pessoas em primeiro lugar: a ética do desenvolvimento e os problemas do mundo globalizado. São Paulo: Companhia das Letras, 2010. cap.7. p. 139-211.

KUHN, D. D. O microcrédito como instrumento de desenvolvimento rural no município de Constantinal RS: a abordagem seniana de desenvolvimento. 2003. Dissertação (Mestrado em Desenvolvimento Rural) - Universidade Federal do Rio Grande do Sul, Faculdade de Ciências Econômicas, Porto Alegre, 2004.

MAKDISSI, P. On definition of economic efficiency. Centre interuniversitaire sur le risque, les politiques économiques et l'emploi - CIRPÉE. Cahier de recherché: 06-44. p.2-6, nov. 2006.

MARIN, S. R. QUINTANA, A. M. Amartya Sen e a escolha social: uma extensão da teoria da justiça de John Rawls? In: Encontro Regional de Economia, XIII, 2010, Porto Alegre. ANPEC Sul. 2010. p. 1-18.

McCARTNEY, G.; COLLINS, C.; MACKENZIE, M. What (or who) causes health inequalities: Theories, evidence and implications? Health Policy. v.113, p.221-227, 2013.

MUKHOPADHAYA, P. Efficiency Criteria and Sen-type Social Welfare Function. NUS: National University of Singapore. Department of Economics. Working Paper, n. 0114. nov. 2001. Disponível em: http://www.fas.nus.edu.sg/ecs/pub/wp/wp0114.pdf

NEW ZEALAND. The Social, Cultural and Economic Determinants of Health in New Zealand: Action to Improve Health. National Advisory Committee on Health and Disability Wel- 
lington, New Zealand, 1998.

PARETO, V. Manual de Economia Política. 2.ed. São Paulo: Nova Cultural, 1987.

RAWLS, J. Uma teoria de Justiça. Revisão: Álvaro Vita. 3a. ed. São Paulo: Martins Fontes, 2008.

RELATÓRIO DE DESENVOLVIMENTO HUMANO. A Ascensão do sul: Progresso Humano num Mundo Diversificado. Programa das Nações Unidas para o Desenvolvimento, New York, 2013.

ROBEYNS, I. The capability approach: a theorical survey. Journal of Human Deelopment, v. 6, n.1, Mar., 2005.

ROBBINS, L. Interpersonal Comparisons of utility: A comment. The Economic Journal, v. 48, n. 192, p. 635-641, Dec. 1938. Disponível em: <http://www.jstor.org/stable/2225051>.

ROBBINS, L. An essay on the nature and significance of economic Science. 2a Ed., London: Macmillan, 1935.

RUGER, J. P. Health and social justice. Public Health, v.364, p.1075-1080, Sep., 2004.

SAMUELSON, P. A. Fundamentos da Análise Econômica. 2. Ed. São Paulo: Editora Nova Cultura Ltda., 1983.

SEN, A. K. Equality of what? The Tanner Lectures on Human Values. 1979.

SEN, A. K. Development: Which Way Now? The Economic Journal, v. 93, n. 372, p.745-762, 1983.

SEN, A. K. Well-Being, Agency and Freedom: The Dewey Lectures 1984. The Journal of Philosophy, v. 82, n. 4, p. 169-221, Apr., 1985.

SEN, A. K. The Concept of Development. In: CHENERY, H., SRINIVASAN, T. H. (Eds.). Handbook of Development Economics, v. 1, Elsevier Science Publishers B. V.; cap.1, p.10-26, 1988.

SEN, A. K. Development as Capability Expansion. In: GRIFFIN K., KNIGHT, J. (Eds.). Human Development and the International Development Strategy for the 1990s. London: MacMillan, 1990, p. 41-58.

SEN, A. K. Mortality as an indicator of economic success an failure. The Economic Journal, n. 108, p.1-25, Jan., 1998.

SEN, A. K. Sobre ética e economia. São Paulo: Companhia das Letras, 1999a.

SEN, A. K. Pobreza e fomes: um ensaio sobre direitos e privações. Lisboa: Terramar, 1999b.

SEN, A. K. Desenvolvimento como liberdade. São Paulo: Companhia das Letras, 2000.

SEN, A. K. ¿̇Por qué La equidad en salud? Rev Panam. SaludPublica / Pan Am J Public health, v.11, n.5/6, p. 302-309, 2002.

SEN, A. K. Capability and Well-being. In: HAUSMAN, D.M. The Philosophy of Economics: An Anthology. Third Edition. Cambridge University Press. Universityof Wisconsin Madison. p. 271-299, 2007.

SEN, A. K. Desigualdade Reexaminada. 2. ed. Rio de Janeiro: Record, 2008.

SEN, A. K. Desenvolvimento como liberdade. São Paulo: Companhia das Letras, 2010a.

SEN, A. K. A Ideia de Justiça. São Paulo: Companhia das Letras, 2011.

SEN, A. K. Desigualdade Reexaminada. 3. ed. Rio de Janeiro: Record, 2012.

SEN, A. K. Por que equidade em saúde. In: SEN, A. K.; KLIKSBERG, B. As pessoas em primeiro 
lugar: a ética do desenvolvimento e os problemas do mundo globalizado. Trad.: Bernardo Ajemberg e Carlos Eduardo Lins da Silva. São Paulo: Companhia das Letras, 2010b. cap. 5. p. 73-93.

SMITH, A. A riqueza das nações. Vol. I e II. São Paulo: Martins Fontes, 2003.

VIEIRA-DA-SILVA, L. M.; ALMEIDA FILHO, N. Equidade em saúde: uma análise crítica de conceitos. Cad. Saúde Pública, Rio de Janeiro, v. 25, n.2, p.217-226, 2009.

WAGSTAFF, A.; PACI, P.; van DOORSLAER, E. On the measurement of inequalities in health. Soc Sci Med, n.33, p.545-557, 1991.

WHITEHEAD, M. The concepts and principles of equity and health. Targets for health for all. Copenhagen: WHO Regional Office for Europe, 1990.

WHITEHEAD, M.; DAHLGREN, G. Concepts and principles for tackling social inequities in health: Levelling up Part 1. World Health Organization 2006, reprinted 2007.

WOODWARD, Alistair. KAWACHI, Ichiro. Why reduce health inequalities? J Epidemiol Community Health. v. 54, p. 923-929, 2000.

\section{Sobre os autores}

Giana Silva Giacomelli - gianagiacomelli@gmail.com

Programa de Pós-Graduação em Administração (PPGA), Universidade Federal de Santa Maria (UFSM), Santa Maria, RS

Solange Regina Marin - solange.marin@ufsc.br

Departamento de Economia e Relações Internacionais, Universidade Federal de Santa Catarina (UFSC), Florianópolis, SC.

Paulo Ricardo Feistel - prfeistel@gmail.com

Programa de Pós-Graduação em Economia e Desenvolvimento (PPGE\&D), Universidade Federal de Santa Maria (UFSM), Santa Maria, RS.

\section{Sobre 0 artigo}

Recebido em 16 de junho de 2015. Aprovado em 22 de janeiro de 2016. 